\title{
Pharmacy Patronage: Identifying the Roles of Nepalese Pharmacists in Tacking COVID-19
}

\author{
Asmita Priyadarshini Khatiwada ${ }^{1 *}$ (D) and Sunil Shrestha ${ }^{1,2 *}$ (D) \\ ${ }^{1}$ Department of Pharmaceutical and Health Service Research, Nepal Health Research and Innovation \\ Foundation, Lalitpur, Nepal. ${ }^{2}$ Department of Pharmacy, Nepal Cancer Hospital and Research Center Pvt. Ltd, \\ Lalitpur, Nepal.
}

\begin{abstract}
Coronavirus disease (COVID-19) pandemic is one of the dire issues currently worldwide. With increasing death tolls every day and with new information regarding disease every minute, it is very important to disseminate the updated and reliable information to the public. Along with other health care professionals, the pharmacists' role is crucial in preventing the spread and management of the disease. The involvement of pharmacists from clinical trials, drug evaluation to providing pharmaceutical care and other basic pharmacy services in the frontline in this health emergency is undeniable. This commentary focuses on the role of pharmacists in different settings of the health care system and the degree of recognition of the work in Nepal.
\end{abstract}

Keywords: Clinical pharmacy, community pharmacy, COVID-19, hospital pharmacy, Nepal, Pharmacist

*Correspondence: asmita.khatiwada2@gmail.com; sunilcresta@gmail.com

(Received: April 09, 2020; accepted: April 21, 2020)

Citation: Khatiwada AP, Shrestha S. Pharmacy Patronage: Identifying the Roles of Nepalese Pharmacists in Tacking COVID-19, J Pure Appl Microbiol. 2020;14(suppl 1):937-943. doi: 10.22207/JPAM.14.SPL1.31

C The Author(s) 2020. Open Access. This article is distributed under the terms of the Creative Commons Attribution 4.0 International License which permits unrestricted use, sharing, distribution, and reproduction in any medium, provided you give appropriate credit to the original author(s) and the source, provide a link to the Creative Commons license, and indicate if changes were made. 


\section{INTRODUCTION}

Coronavirus disease (COVID-19) is one of the deadly infectious diseases of the century affecting all the countries worldwide and has been declared as a global health emergency by the World Health Organization (WHO) on January 30, 2020. According to WHO, there are $2,241,359$ reported cases and 152,551 deaths due to COVID-19 as of April 19, 2020. ${ }^{1}$ COVID-19 is caused by severe acute respiratory syndrome coronavirus 2 (SARS-COV2). The symptoms of the disease are mild including fever, cough, shortness of breath, malaise, etc., however, the patients remain asymptomatic for quite a few days which makes the early detection more challenging. ${ }^{2}$ Elderly people and people with comorbidities such as cardiovascular disease, diabetes, chronic respiratory disease, etc. are at higher risk. ${ }^{2-4}$

During this period of a pandemic, the role of all health care providers including doctors, nurses, pharmacists and other paramedics is crucial. Doctors and nurses stand as the frontline warriors in this uphill battle. Not only many doctors and nurses, but even many pharmacists are also at high risk and have lost their lives fighting with this pandemic. Pharmacists working in the community and hospital settings play an important part in the prevention of the spread of the COVID-19. The role of pharmacists in the management of disasters and infectious diseases is well documented. ${ }^{5-9}$

Role of community pharmacists

Community pharmacies are the first point of contact for local people for minor ailments where hospitals are not available nearby. As the symptoms of the COVID-19 are mild, people have mistaken it with normal common cold, flu or fever and approach community pharmacies for the management. Also, the prescribers may postpone non-urgent appointments making the community pharmacies and pharmacists the focal point for health care services. So, the community pharmacies should be responsible for testing, early detection and immediate referral. A study in Macau has highlighted the importance of community pharmacists in contributing to the management of the COVID-19 outbreak. Community pharmacists in Macau were given the responsibility of early identification and appropriate referral of the patients, supply of medicines, circulation of information to the public regarding the local situation, overall infection progress and measures for personal protection and prevention of the spread of COVID-19. Also, the charge of the government approach "The Guaranteed Mask Supply for Macao residents Scheme" was given to the pharmacists. ${ }^{10}$ Realizing the importance of masks to curtail the spread of the infection, under this scheme, pharmacists were responsible to ensure appropriate supply of the masks to the public at a rational price.

Social media has an important part to play in information dissemination and creating awareness among masses as most people have smart phones and access to the internet. However, the information and news available may be bias and bogus without any reliability and validity. Though social media and online communication have reached every corner of the country these days, there might be some community/ regions beyond the reach of it. The community pharmacies act as an information center for the local people in such areas regarding the disease, signs, and symptoms, preventive measures, mode of spread, appropriate steps to take if someone develops any initial symptoms, etc. Pharmacists have a key role in the continual supply of pharmaceuticals and hygiene products, providing updated information to the community on disease and advising personal protection skills and ways to prevent further spread to the public (like optimal hand hygiene, social distancing, staying home, etc.). ${ }^{10}$ Additionally, the pharmacists can guide the public on searching the reliable source of information about the disease like Centers for Disease Control and Prevention (CDC), WHO, local public health departments. ${ }^{8}$ A study in China showed that in this health crisis, the queries from patients have shifted from regular medication queries to queries about COVID-19 including basic information like mask selection, signs and symptoms of the disease and the preventive measures to be taken. ${ }^{11}$

With the major concern of the hospitals towards COVID-19 and increasing patient volume for the relevant symptoms, the responsibility of community pharmacies may expand in managing the minor ailments and refilling the prescriptions for patients with long term disease. Innovative approaches may be utilized by the pharmacists/ pharmacies maintaining the social distance yet serving the community. For example, delivery 
systems of medications can be initiated along with video consultation and advising the patient. ${ }^{12}$ Role of clinical and hospital pharmacists

The role of clinical pharmacists and hospital pharmacists working in a hospital in providing patient care in this crisis can't be ignored. Clinical pharmacists can act as mediator among patients and physicians for optimizing the therapy in all patients within the hospital. Many studies are being conducted for the identification of appropriate agents as a treatment of COVID-19 and many articles, guidelines and data are available. Clinicians might have increased patient flow leaving them with less or no time left to read and evaluate the published information and pharmacist can play a significant role in the interpretation of those scientific literature providing them with factual information. ${ }^{8}$ Pharmacists' role as the drug information provider is key to educate, train and inform other healthcare professionals with the updated information regarding COVID-19 and proper utilization of the protective materials. Also, clinical pharmacists are responsible for monitoring treatment outcomes and the occurrence of any adverse effects in patients. ${ }^{13}$

The drug information service by the pharmacists is crucial in this pandemic. In the situation of panic, people are inclined towards any sort of information regarding COVID-19 and ways to prevent it. Not all the information that reaches the public is reliable and accurate. The pharmacists can act as a provider of accurate and authentic information through drug information centers (DIC). ${ }^{14}$ As a result of a statement from United States (US) President Donald Trump stating that hydroxychloroquine in combination with azithromycin is the cure for COVID-19, there was a shortage of hydroxychloroquine for the patients who need it (patients of lupus, rheumatoid arthritis, malaria). In Arizona, the state in the southwestern region of the US, a couple administered the nonmedical version of chloroquine to be safe from the disease after hearing out Trump's response for the effectiveness of the drug against COVID-19 and one of them died and the other was in serious condition in hospital. Moreover, there were cases of overdose of chloroquine when used as a treatment for COVID-19 along with its price surge in Nigeria. ${ }^{15-17}$ These are some of the few examples of how broadcasting bias information without any scientific basis can lead to harmful consequences. DICs in hospitals and communities can play a significant role in the dissemination of objective information about the disease and the medicines without misleading the public. DICs can be made active via the use of technology such as phone calls, emails, social media, etc.

With the outbreak of new disease, new drugs need to be investigated and in the process of drug discovery, pharmacists play a very important role in supporting the investigational drug studies and monitoring adverse effects. Clinical pharmacists' role is identified in coordinating the process of study from selecting suitable patients for use of the investigational agents, collaborating with the investigator, providing the drug to the patient's bedside to the monitoring of patients. ${ }^{8}$ In Australia, to develop and circulate a single, non-confusing and continually updated guideline for the clinicians to follow, Australian health professional groups including the Society of Hospital Pharmacists of Australia (SHPA) came together. The medicine expertise has been provided by the representatives of SHPA to assist the review of national and international clinical guidelines ensuring that the health care providers have access to the reliable and updated information in this crisis. ${ }^{6}$

Hospital pharmacists should take the responsibility of providing safe and effective medications to the patients and should be ready to tackle any drug shortages during the pandemic. This global threat will lead to a crisis of raw materials for the manufacturing of new batches of medicine which may result in prescriptions of suboptimal drugs to patients. So, identification of safe and effective therapeutic alternatives, developing strategies for tackling the drug shortages and if necessary, prioritization of medication supply to the ones who are most likely to benefit are the steps to be taken by pharmacists. ${ }^{8}$ Hospital pharmacists are also responsible for counseling and promoting hospital prevention and infection control. ${ }^{13}$

A study conducted in Northeast China showed the efficient working of pharmacists in the COVID-19 crisis. Pharmacists have involved in the effective supply of drug and pharmaceutical care to the patients and continuous adverse 
effects monitoring. No nosocomial infections and medication errors were reported within the hospital and improvement in the health of the patients along with proper control of the disease was observed. ${ }^{18}$ This highlights the extent of the importance of pharmacists' activities in the prevention of spread and control of the infection. Current scenario of pharmacist and their roles during COVID-19 in Nepal

Even though the role of pharmacists in preventing the spread of COVID-19 has been identified in other countries, ${ }^{6,10,11,18}$ it doesn't seem to be the topic of talk in Nepal. The first case of COVID-19 was diagnosed on January 25,2020 , and till now there are 31 reported cases of COVID-19 with one local transmission. ${ }^{1,19}$ The Government of Nepal hasn't developed any guidelines for the pharmacist working in different areas. Even though pharmacists have been involved in the dispensing of medicine and counseling of patients/patients' parties in hospital and community working in the frontline, they are still underrated warriors in the fight with COVID-19. However, Nepal's leading pharmaceutical organizaton, Nepal Pharmaceutical Association (NPA), Hospital Pharmacists Association of Nepal (HosPAN), Pharmacy Association of Nepal (PhAN) with Nepal Pharmacy Council and Kathmandu University developed a guideline, titled "COVID-19: guidelines for pharmacist and pharmacy assistant" for Nepalese pharmacy professionals working in different settings..$^{20}$ The government declared that the frontline health care workers will be provided with additional remuneration highlighting the doctors and nurses. Pharmacists are being constantly exposed to the numerous patients/ patient parties which emphasize the need for the personal protection equipment (PPE) but it seems to be in short for the pharmacists. Be it in the community or hospital, pharmacists have direct contact with patients while counseling, dispensing drugs, receiving prescriptions, reviewing treatment charts of patients, interacting with other healthcare professionals and patient parties. This increases the risk of pharmacists being infected and be the cause for spread of the infection. The efforts of pharmacists in preventing the spread of the disease have gone unrecognized by the people and the government as well. In India (neighboring country of Nepal) as well, the personnel working in authorized bodies of pharmacy have told that their efforts are not well recognized and considered by the government as of now. ${ }^{21}$ The active involvement of pharmacists from their level in the prevention of spread, in creating awareness about COVID-19, ways of spread and home care guidance in the community and hospital through reliable source maintaining social distance might aid in the identification of the vital role of pharmacists in this unprecedented crisis. Besides, assisting the clinicians in clinical decision making by providing them with up-to-minute authentic information and updated national and international clinical guidelines and providing effective training to health care providers within the institution highlights the need of pharmacists in a fight with COVID-19. In the current situation, pharmacists can be involved in the compounding of sanitizers and disinfectants to meet the uphill demand of these supplies. Further, managing the stable distribution of the medications and protective facilities without creating shortages within hospitals and community settings emphasizes the importance of pharmacists in proper drug supply. The continual supply of essential medicines, PPEs for every frontline health care provider, facemasks, sanitizers and disinfectants and surgical accessories in hospitals should be ensured nationwide in this critical situation. Additionally, pharmacists are also needed to be provided with proper education about the handling of diseases and steps to be taken for self-protection.

China's approaches on the control of COVID-19 and what other countries can learn

China's efforts for controlling the spread of COVID-19 over a short period are commendable. Due to the lack of strict guidelines in the early days of the pandemic in Wuhan, the country had lost the lives of many citizens. Considering the scenario, before a single occurrence of the outbreak in other provinces of China, they adopted different approaches to control and prevent the spread of COVID-19. The Chinese universities were actively involved in mental health maintenance, medical rescue and emergency management, alumni resource collection, control of staff mobility and new methods in online education models. ${ }^{22}$ The testing and screening kits for the disease were made available in sufficient amounts within a short duration to speed up the detection. The proactive 
government of different provinces disseminates the clear guidance about lockdown (the degree and scope), social distancing, avoiding any gatherings and track down their implementation by the public. Many teams of health care professionals were assigned and mobilized to cope up with the emergency in the country and they were provided with all the required facilities for self-protection and safety. Health QR codes (abbreviated from quick response code) were established for all the people coming to a particular province and existing in the province. The QR codes were of three different color green, yellow and red indicating 'can move freely', 'requires seven-day self-quarantine' and 'requires a 14-day self-quarantine'. Monitoring and recording of the temperature and updating the profile regularly was made mandatory for each individual by the government. The supply of essentials like food was controlled by the government effectively. ${ }^{23}$ The cases of COVID-19 were confirmed through different fever clinics with sufficient medical staff all around the country where the people were screened and suspected cases were isolated and non-COVID 19 patients were excluded..$^{24}$ Additionally, the pharmacists in China have acted effectively in this public health crisis. The several approaches to mention include providing suitable guidelines to in act for pharmacists and pharmacies, drafting emergency formularies, monitoring and solving drug shortages, public education on infection prevention and management, providing pharmaceutical care, establishing remote pharmacy facilities to avoid human-human infections and active participation on drug evaluation and clinical trials. ${ }^{25}$

Meanwhile, in New Zealand, pharmacies were provided with resources like posters, information leaflets, images for public about preventing COVID-19 by Ministry of Health. Also, telephonic service was made available by issuing emergency Healthline number for public to get any infection related information and any supplies needed from pharmacies avoiding visits in public. ${ }^{26}$

\section{CONCLUSION}

Nepal, being a country surrounded by China and India where the effect of COVID-19 hasn't been hidden to the world, is at utmost risk for infection. Also, Nepal is not as developed as the other two countries and most of the regions here lack suitable health care facilities to fight against COVID-19. In such a critical situation, only prevention of the spread of the disease is the major focus of the country. Pharmacists working in different settings such as community and hospital can take responsibility to make the public aware of appropriate information about the disease in their community. The regular supply of medicines and patient compliance can be ensured by the pharmacists especially for those taking medications for chronic illness through delivery and telephonic services to limit tour outside the house. The presence of representatives of pharmacists, doctors and relevant health care providers in the committee for tackling COVID-19 at government level might lead to better decision making to deal with the pandemic throughout the country. The mobilization of pharmacists in different healthcare settings and formulating standard procedures to be followed by every frontline pharmacist and pharmacy can be planned at the government level with full support from the government for better management of COVID-19 and better dissemination of disease and medicinerelated information to the public.

\section{ACKNOWLEDGMENTS}

The author(s) would like to acknowledge Senior Pharmacist Mr. Bibek Singh Mahat and Assistant Professor Anup Luitel (Department of Pharmacy, Kathmandu University) for providing information regarding Covid19: Guidelines for pharmacists and pharmacy assistants which was issued by different pharmaceutical organizations of Nepal.

\section{AUTHORS' CONTRIBUTION}

Both authors participated in conceptualization, drafting and revision of the manuscript. Both authors have read and approved the final text of the manuscript.

\section{CONFLICT OF INTEREST}

The authors declares that there is no conflict of interest.

\section{FUNDING}

None. 


\section{ETHICS STATEMENT}

This article does not contain any studies with human participants or animals performed by any of the authors.

\section{AVAILABILITY OF DATA \\ Not applicable.}

\section{REFERENCES}

1. World Health Organization. Coronavirus disease 2019 (COVID-19) Situation Report- 90. 2020. https:// www.who.int/docs/default-source/coronaviruse/ situation reports/20200419-sitrep-90-covid-19. pdf?sfvrsn=551d47fd_2, Accessed 19 April, 2020.

2. Cascella M, Rajnik M, Cuomo A, Dulebohn SC, Di Napoli R. Features, evaluation and treatment coronavirus (COVID-19). [Updated 2020 April 6]. In: StatPearls [Internet]: Treasure Island (FL): StatPearls Publishing; 2020.

3. Guan W-j, Liang W-h, Zhao $\mathrm{Y}$, et al. Comorbidity and its impact on 1590 patients with Covid-19 in China: A Nationwide Analysis. Eur Respir J, 2020: 2000547. https://doi.org/10.1183/13993003.01227-2020

4. Wang L, He W, Yu X, et al. Coronavirus Disease 2019 in elderly patients: characteristics and prognostic factors based on 4-week follow-up. J Infect. 2020. https://doi. org/10.1016/j.jinf.2020.03.019

5. Centers for Disease Control and Prevention. Considerations for Pharmacies during the COVID-19 Pandemic. https://www.cdc.gov/coronavirus/2019ncov/healthcareresources/ pharmacies.html [ Accessed 4 April, 2020]

6. Society of Hospital Pharmacists of Australia. Hospital pharmacists in new national taskforce to support clinicians providing COVID-19 care. https://www. shpa.org.au/news/hospitalpharmacists-new-nationaltaskforce-support-clinicians-providing-covid19-care [Accessed 5 April, 2020]

7. Watson KE, Singleton JA, Tippett V, Nissen LM. Defining pharmacists' roles in disasters: A Delphi study. PLoS ONE. 2019;14(12):e0227132. https://doi.org/10.1371/ journal.pone.0227132

8. Gross $A E$, MacDougall C. Roles of the clinical pharmacist during the COVID-19 pandemic. J Am Coll Clin Pharm. 2020. https://doi.org/10.1002/jac5.1231

9. Shrestha S, Kandel P, Danekhu K, Bhuvan KC. Reflecting on the role of a pharmacist during the two major earthquakes of 2015: Are we prepared for similar future disasters? Res Social Adm Pharm. 2019;15:15001501. https://doi.org/10.1016/j.sapharm.2019.03.006

10. Ung COL. Community pharmacist in public health emergencies: Quick to action against the coronavirus 2019-nCoV outbreak. Res Social Adm Pharm. 2020;16:583-586. https://doi.org/10.1016/j. sapharm.2020.02.003

11. Zheng SQ, Yang L, Zhou PX, Li HB, Liu F, Zhao RS. Recommendations and guidance for providing pharmaceutical care services during COVID-19 pandemic: A China perspective. Res Social Adm Pharm.
2020. https://doi.org/10.1016/j.sapharm.2020.03.012

12. Cadogan $\mathrm{CA}$, Hughes $\mathrm{CM}$. On the frontline against COVID-19: Community pharmacists' contribution during a public health crisis. Res Social Adm Pharm. 2020. https://doi.org/10.1016/j.sapharm.2020.03.015 International Pharmaceutical Federation. COVID-19: Guidelines for Pharmacists and the Pharmacy Workforce. 2020. https://www.fip.org/files/content/ priority-areas/coronavirus/Coronavirus-guidanceupdate-ENGLISH.pdf [Accessed 5 April, 2020]

14. Shrestha S, Khatiwada AP, Gyawali S, Shankar PR, Palaian S. Overview, challenges and future prospects of drug information services in Nepal: a reflective commentary. J Multidiscip Healthc. 2020;13:287-295. https://doi.org/10.2147/JMDH.S238262

15. The Intercept. After Trump Hyped Chloroquine as a Covid-19 Cure, a Man Died Trying to Self-medicate with a version of the chemical used in fish tanks. https://theintercept.com/2020/03/24/trump-hypedchloroquine-cure-covid-19-man-arizona-took-died/ , Accessed 20 April, 2020.

16. The Guardian. Trump touts hydroxychloroquine as a cure for Covid-19. Don't believe the hype. https:// www.theguardian.com/international [ Accessed 20 April, 2020]

17. Nature World News. Price Spike, Chloroquine Overdose Cases in Nigeria due to Use of Chloroquine as COVID-19 Medicine. https://www.natureworldnews.com/ articles/43550/20200323/chloroquine-covid-19treatment-nigeria.htm , Accessed 20 April, 2020.

18. Ying W, Qian Y,Kun Z. Drugs supply and pharmaceutical care management practices at a designated hospital during the COVID-19 epidemic. Res Social Adm Pharm. 2020. https://doi.org/10.1016/j.sapharm.2020.04.001

19. Bastola A, Shah R, Rodriguez-Morales AJ et al. The first 2019 novel coronavirus case in Nepal. The Lancet Infectious Diseases. 2020;20(3):279-280. https://doi. org/10.1016/S1473-3099(20)30067-0

20. Nepal Pharmaceutical Association, Nepal Pharmacy Council, Hospital Pharmacist Association of Nepal, and Pharmacy Association of Nepal. Covid19: Guidelines for Pharmacist and Pharmacy Assistant for Nepalese Pharmacy Professionals. https://www. fip.org/files/content/priority-areas/coronavirus/ mo-resources/NEPAL_Final_Guideline_COVID. pdf?fbclid=IwAR3wCib-iuiOPLH4aiK1lkqo4DdxKLwGIZ Xe2IZifP_43vFltWdop_mPYE, Accessed 19 April, 2020.

21. Outlook. Corona Warriors: 'PM Modi Ignored Us,' Say Pharmacists as Gadkari Opens Old Wound. https:// www.outlookindia.com/website/story/india-newscorona-warriorspm-modi-ignored-us-say-pharmacistsasgadkari-opens-old-wound/349665, Accessed 7 April, 2020.

22. Wang C, Cheng Z, Yue XG, McAleer M. Risk Management of COVID-19 by Universities in China. J Risk Financial Manag. 2020;13(2):36. https://doi.org/10.3390/ jrfm13020036

23. 6 lessons from China's Zhejiang Province and Hangzhou on how countries can prevent and rebound from an epidemic like COVID-19. [ Accessed 19 April, 2020]

24. Wang H, Wang S, Yu K. COVID-19 infection epidemic: 
Khatiwada \& Shrestha | J Pure Appl Microbiol | 14(suppl 1):937-943 | May 2020 | https://doi.org/10.22207/JPAM.14.SPL1.31

the medical management strategies in Heilongjiang Province, China. 2020;1-4. https://doi.org/10.1186/ s13054-020-2832-8

25. Liu S, Luo P, Tang M, Hu Q, Polidoro JP, Sun S, Gong Z. Providing pharmacy services during the coronavirus pandemic. Int J Clin Pharm. 2020;1-6.

26. COVID-19: Guidance provided by the society for pharmacy. https://doi.org/10.1016/j.ptdy.2020.04.011 